\title{
Imprensa local como ouvidoria pública
}

\author{
Local press as a public ombudsman
}

La prensa local como defensoría pública

Rosa Mirah Araújo Gomes Lacerda

- Graduada em Jornalismo pelo Instituto de Educação Superior de Brasília (lesb)

- Jornalista do Instituto Muito Especial (Rio de Janeiro, RJ), de inclusão social e profissional das pessoas com deficiência e de orientação das organizações a lidarem com a diversidade

-rosamirah@yahoo.com.br 
Resumo

Novas tecnologias difundiram o acesso à informação, ampliando a autonomia do público. Nesse contexto, a imprensa local lança o olhar para as demandas das comunidades e assume o papel de mediadora entre os problemas da população e os órgãos públicos. O jornal local atua como uma ouvidoria pública informal, priorizando casos que envolvam o governo e usando a exposição e o constrangimento como ferramenta eficaz na busca por soluções.

PALAVRAS-CHAVE: IMPRENSA LOCAL • COMUNIDADE • OUVIDORIA PÚBLICA

\section{Abstract}

New technologies have disseminated access to information, broadening the public's independence. In this context, the local press looks at the community demands and assumes the role of a mediator between the population's problems and the governmental bodies. The local news acts as an informal public ombudsman, focusing on cases that involve the government and using exposure and embarrassment as efficient tools for the quest for solutions.

KEYWORDS: LOCAL PRESS • COMMUNITY • PUBLIC OMBUDSMAN

Resumen

Las nuevas tecnologías difundieron el acceso a la información y ampliaron la autonomía del público. En este contexto, la prensa local lanza su mirada a las demandas de las comunidades y asume el papel de mediadora entre los problemas de la población y los órganos públicos. El periódico local actúa como una defensoría pública informal y prioriza casos en los que está involucrado el gobierno, usando la exposición y la cohibición como herramientas eficaces en la busca de soluciones.

PALABRAS CLAVE: PRENSA LOCAL • COMUNIDAD • DEFENSORÍA PÚBLICA 
Este trabalho procura analisar o jornalismo local e o viés comunitário adoEtado por veículos que atuam como ouvidorias públicas para a comunidade. Para identificar as características do novo modelo, é preciso conhecer quais fatores levaram ao seu surgimento e como a imprensa se adaptou às mudanças ao longo do tempo.

\section{JORNALISMO E INFLUÊNCIA SOCIAL}

Segundo os autores Bill Kovach e Tom Rosenstiel (2004), o jornalismo é uma evolução da comunicação entre as pessoas, do instinto de percepção que nos faz querer trocar informações e experiências. A retórica, arte do uso persuasivo da fala e da escrita, é um instrumento valorizado desde as primeiras civilizações. Asa Briggs e Peter Burke (2004, p. 11) citam a importância da retórica em Roma e na Grécia antiga, onde acontecimentos de interesse público circulavam oralmente pelo Mercado de Atenas.

O jornalismo moderno surgiu no início do século XVII. Kovach e Rosenstiel (2004, p.37) explicam que, em Londres, os cafés eram palco de discussões acaloradas sobre acontecimentos da Inglaterra e de outros países. Com o tempo, os cafés passaram a se especializar em assuntos específicos, como política e economia, e as informações reveladas durante os debates eram registradas. Os primeiros jornais surgiram por volta de 1609 , sendo o conteúdo tirado desses cafés.

O avanço das técnicas de impressão contribuiu para a popularização do jornalismo. Com o aumento da capacidade de publicação, os jornais passaram a ser vendidos a preços populares, conquistando maior alcance. A imprensa ganhava um público diversificado, com interesses distintos. Briggs e Burke (2004, p.192) explicam que os jornais ampliaram sua atuação, mesclando informação e entretenimento.

Com um conteúdo abrangente, a imprensa alcançava importantes níveis de influência nas massas. Briggs e Burke (2004, p. 192) citam o jornal londrino Daily Mail, lançado em 1896, como o primeiro diário a dedicar uma página às mulheres. O termo "quarto poder", adotado pelo britânico The Times como uma autodefinição, foi difundido pela imprensa europeia. Nos Estados Unidos, onde os meios de comunicação tinham sua liberdade defendida pela Constituição, a imprensa também se consolidou como instrumento de forte influência social.

Ao longo do tempo, a imprensa evoluiu e ampliou seu alcance, sempre beneficiada por tecnologias que multiplicaram as possibilidades de comunicação.

1 Briggs e Burke (2004, p. 192) afirmam que a expressão de "quarto poder" foi criada na Inglaterra, pelo historiador Macaulay, em referência à Galeria de Imprensa do Parlamento. Logo, o jornal The Times, 0 mais popular em Londres, passou a se definir como "quarto poder". A expressão foi adotada para definir a influência da imprensa. 
Telégrafo, telefone, televisão e rádio são algumas das inovações que foram utilizadas pelo jornalismo como ferramentas de difusão. Mas, com o surgimento da internet, a imprensa se deparou com uma mudança de contexto radical.

Criada durante a Guerra Fria, a internet servia para garantir a comunicação entre as forças armadas norte-americanas. Segundo Kellen Cristina Bogo (2000), em 1990, o inglês Tim Bernes criou a world wide web, rede mundial de computadores que armazenava documentos em diferentes mídias. A internet ganhava cores, imagens, sons e janelas que se abriam para infinitas possibilidades. Seguindo a nova tendência, empresas de computadores criaram navegadores (browsers), como o Internet Explorer, da Microsoft, que facilitavam o acesso. Logo, a multiplicidade de funções da rede foi percebida pela sociedade. A tecnologia passou a ser usada para vender, comprar, estudar, conhecer outros lugares e pessoas.

Em um primeiro momento, o jornalismo usava a internet como mais um veículo para divulgar as notícias no formato tradicional. Cláudia Irene de Quadros (2002, p. 243) explica que rapidamente grandes empresas jornalísticas transferiram seu conteúdo para a internet e perceberam que o jornalismo online demandava linguagem, abordagem e profissionais específicos.

Segundo a autora, o jornalismo precisou adaptar sua pragmática para se valer das possibilidades que a internet proporcionava. As notícias tinham um alcance maior e podiam ser atualizadas à medida que outros fatos aconteciam. Outra inovação que teve importância fundamental para a linguagem da internet foi o hipertexto. A ferramenta possibilita que uma notícia seja relacionada a uma infinidade de janelas, com textos, imagens e links que complementam o fato. Com o recurso, cabe ao leitor decidir o quanto quer se aprofundar no tema. Nesse contexto, uma nova tendência de comunicação começa a aparecer, com formato livre e opinativo, podendo ser praticada tanto por um profissional quanto por qualquer cidadão com acesso à internet.

A internet permitiu que as pessoas pudessem construir seu próprio jornal diário, composto por fontes diversas. Não é preciso ler um jornal inteiro para saber dos acontecimentos da cidade ou de segmentos como economia, saúde ou educação. O leitor da internet pode recorrer aos portais de notícias para ter um balanço dos principais fatos no País e no mundo e depois direcionar a busca para notícias de seu interesse. Pode também comentar as notícias que viu e até mesmo produzir informações.

Com inovações como os portais de notícias, blogs, canais de vídeos, com programação independente e democrática, e outras tantas novidades que surgem a cada instante, revistas semanais, jornais impressos e noticiários televisivos locais, tiveram de se adaptar para garantir o interesse do público, em meio à sedução do tempo real. 


\section{JORNALISMO LOCAL E O NOVO PÚBLICO}

No cenário de multiplicidade de informações, o jornal local não pode competir com a abrangência e rapidez da internet. Para manter-se diante de uma concorrência acirrada, ele passa a focar a realidade comunitária valorizando suas peculiaridades, seu cotidiano e suas demandas, preservando, assim, a ligação com o público.

Jornais locais passaram a percorrer as comunidades e se depararam com um cenário de mobilização, pessoas unidas, conscientes de seus direitos e indignadas com as situações de descaso a que são submetidas. Essa valorização da identidade comunitária é reflexo de processos sociais e econômicos.

Cleofe Sequeira e Francisco Bicudo (2006, p. 1) avaliam que o desenvolvimento econômico e tecnológico tem grande impacto no comportamento da sociedade. O capitalismo reorganizou as estruturas sociais e as relações de trabalho. Houve o aumento da concentração de renda e, por consequência, da exclusão social.

Na visão desses autores, o capitalismo promove duas situações contraditórias que têm consequência direta na sociedade. A primeira é a de concentração versus fragmentação. A concorrência do mercado força grandes investimentos em tecnologias para que se obtenha a liderança em produtos e serviços. Assim, o poder fica direcionado a poucas empresas gigantes, que determinam onde e como os bens e serviços serão produzidos. Por outro lado, essas empresas precisam competir entre si, em preço e qualidade, o que resulta na fragmentação do processo, com terceirizações e franquias.

A segunda relação contraditória é a de exclusão versus inclusão. O desemprego nas populações é crescente. Mas o capitalismo estimula a concorrência e a queda de preços, inserindo regiões que antes não tinham poder de consumo. Os autores mostram que, com o tempo, essa relação contraditória ampliou o hiato social. As classes mais pobres, sem potencial de consumo, foram posicionadas no sistema capitalista, sem participar de seu desenvolvimento. Os trabalhadores contribuíam para os processos de produção, mas eram alienados da realidade do consumo. Sequeira e Bicudo (2006, p.3) recorrem à teoria de Karl Marx para explicar que a alienação ocorre em três fases:

[Pimeiro], na relação do trabalhador com o produto do seu trabalho como algo exterior a ele, como um objeto estranho que o domina. O trabalhador não dispõe do produto do seu trabalho: fabrica o carro, mas não tem carro [...]. Segundo, na relação do trabalhador com sua própria atividade. O trabalho é exteriorizado dele porque não trabalha para si, mas para outro [...]. Terceiro, na transformação do caráter da espécie humana, que, de atividade livre e consciente, passa a ser atividade como meio de subsistência física e individual. 
Alienada do processo de trabalho, a população pobre se vê também excluída dos processos políticos. O povo segue à margem do desenvolvimento, não participa do planejamento e da tomada de decisões de sua cidade ou país e sua contribuição limita-se ao pagamento de imposto.

A exclusão social e a falta de participação pública fizeram com que as camadas mais pobres não se identificassem com o contexto atual. A população, segregada em periferias, se uniu, criando grupos organizados de interesses comuns. O povo buscava um meio alternativo de participação, para lutar por melhores condições e reivindicar uma sociedade mais justa. Os movimentos sociais, promovidos pelas comunidades, refletem a cultura e o cotidiano de seu povo e trazem para a esfera pública suas demandas. Foi a resistência do povo submetido à pobreza que criou mecanismos para praticar a cidadania.

A tendência de mobilização contribuiu para o fortalecimento da identidade da camada popular. Os efeitos alteraram o cenário das comunidades, agora repletas de associações e grupos de interesses diversos. Arte, música, moda, linguagem e outras manifestações culturais, típicas das comunidades, também passam a ser valorizadas.

Unidas em organizações estruturadas e com objetivos direcionados, as classes menos favorecidas assumiram um papel mais ativo na vida pública. O cotidiano das comunidades ganha relevância social e os movimentos urbanos tornam-se instrumentos de modificações políticas e culturais. As ações promovidas pelas comunidades têm com objetivo solucionar problemas que afetem seus moradores. O discurso tem caráter reformista, busca uma organização mais justa na sociedade, mas não levanta bandeiras revolucionárias.

\section{A IMPRENSA A SERVIÇO DA COMUNIDADE}

Segundo Nelson Traquina (2003, p. 9), o conceito de jornalismo comunitário surgiu no fim da década de 1980, tendo, além dessa, outras terminologias, como jornalismo cívico, jornalismo de serviço e jornalismo público. Nos Estados Unidos, a tendência foi motivada pela crise de credibilidade dos meios de comunicação em massa, após as eleições presidenciais em $1998^{2}$. Preocupados, os jornais buscaram identificar o que o público considerava importante. Traquina (2003, p. 10) traz o exemplo do Columbus Ledger Enquirer, da companhia Knight-Ridder, da Geórgia. O jornal iniciou, em 1998, um programa que tinha como objetivo melhorar a vida da comunidade. Foram realizadas sonda-

2 Diz Nelson Traquina (2003) que pesquisas feitas nos Estados Unidos, no início dos anos 1990, apontaram uma considerável queda nos níveis de confiança da população com a mídia. A cobertura das eleições americanas, em 1998, serviu para macular a imagem do jornalismo. A campanha negativa, no estilo 'corrida de cavalos', frustrou as expectativas do público. Questões importantes para os eleitores não foram consideradas. 
gens para descobrir os maiores problemas dos cidadãos. Depois, 85 moradores passaram por questionamentos e entrevistas. Com o resultado dos estudos, o jornal promoveu encontros com a população e lançou o movimento "Unidos para além de 2000”, que buscava solucionar as carências da sociedade.

Traquina cita o jornalista Davis Merritt como um dos precursores da nova tendência ${ }^{3}$. Merritt defende que jornalismo e democracia estão ligados e que a relação dos dois conceitos é simbiótica:

Numa sociedade de indivíduos dispersos e abarrotados com informação descontextualizada, uma vida pública efetiva precisa ter uma informação relevante que é partilhada por todos, e um lugar para discutir as suas implicações. Somente jornalistas livres e independentes podem - mas habitualmente não conseguem - providenciar estas coisas. Do mesmo modo, a vida pública efetiva requer a atenção e o envolvimento de cidadãos conscienciosos, que só eles podem providenciar. Por outro lado, se as pessoas não estão mais interessadas na vida pública, elas não têm qualquer necessidade dos jornalistas nem do jornalismo.(MERRITT, apud MESQUITA; TRAQUINA, 2003, p. 12).

Segundo Traquina, Merritt acredita que o jornalismo se descuidou de suas obrigações com a vida pública, e é responsável pelo mal-estar reinante entre a população e o governo. E que a adversidade entre imprensa e governo se firmou depois da cobertura do escândalo de Watergate.A regra entre os jornalistas era "apanhar ladrões", o que desgastou a relação de interesse mútuo entre governo e mídia. "À medida que o cão de guarda se transformou num cão de ataque, os piores aspectos da cultura jornalística ficaram mais visíveis" (MERRITT, apud MESQUITA; TRAQUINA, 2003, p. 13).

Mesquita (2003, p.19) analisa que o jornalismo precisou adaptar sua pragmática para restabelecer uma ligação com a sociedade, ficando atento à comunidade e procurando detectar as questões mais relevantes.

\section{IMPRENSA LOCAL COMO OUVIDORA PÚBLICA DAS COMUNIDADES}

Para fazer jornalismo voltado para a comunidade, o profissional deve abandonar os modelos clássicos e padronizados de reportagem. Segundo Felipe Pena (2004, p. 187), o jornalista de um veículo comunitário deve saber pensar como a comunidade, decifrar a visão que os moradores têm de si, reforçando suas identidades e seus valores.

3 Em 1992, Merritt lançou um projeto inovador no jornal que dirigia, o Wichita Eagle. 0 "People project: solving it ourselves" consistia num consórcio entre empresas jornalísticas, que discutiam os problemas das comunidades e convidavam moradores a participar dos debates. Cada questão publicada no Wichita Eagle era acompanhada de uma lista de órgãos e instituições envolvidos (MERRITT, 2003). 
Sequeira e Bicudo ressaltam a entrevista feita com o professor da Universidade Estadual Paulista (Unesp), Pedro Celso Campos (2006, p. 7-8), para quem o jornalista comunitário deve estabelecer vínculo com seu público:

A proximidade entre as pessoas é a principal característica do meio comunitário. As pessoas se conhecem e se reconhecem [...] nos seus problemas, angústias, alegrias e ritos cotidianos. Essa reconhecibilidade também exige uma linguagem referenciada aos costumes do grupo social. É uma linguagem, coloquial, de fácil entendimento, reconhecível em suas gírias e modismos.

Para preencher os quesitos necessários a uma cobertura comunitária, a imprensa precisa estabelecer um contato frequente com a população, conhecer as peculiaridades de cada cidade ou bairro. Nesse contexto, Campos (2006, p. 7) acreditam que o jornal local leva vantagem:

No jornalismo comunitário, o local é quem dá as cartas - ou melhor, as pautas. Ele assume com ênfase e sem constrangimentos o fato de procurar dar conta de uma área restrita. [...] Em comparação com os chamados veículos da grande-imprensa, não se importa em ser pequeno [...]. Essa, aliás, é vista como uma de suas grandes virtudes qualitativas, pois o fato de aproximar-se de seu público permite que dialogue com ele com mais profundidade e intensidade.

A comunicação direta com a população e o espaço livre para manifestação permitem que a imprensa identifique as principais demandas de cada lugar. A relação comunitária entre jornalistas e moradores expõe as carências e deficiências de cada lugar, especialmente com relação aos serviços do governo, promovendo o debate entre a sociedade e seus representantes políticos.

Para o deputado federal por São Paulo Celso Russomano (2009), a abertura para uma relação mais direta e participativa com as comunidades propicia que a imprensa atue como uma ouvidoria pública. Em entrevista para este trabalho, o deputado avalia que a população ainda tem pouco conhecimento sobre as ouvidorias de órgãos públicos e as associa a um serviço burocrático e ineficiente.

O Brasil teve seu primeiro ouvidor quando recebia as primeiras capitanias ${ }^{4}$. A atividade evoluiu e, atualmente, as ouvidorias estão presentes nos três poderes. Para Imbroisi (2004), a expansão da ouvidoria pública no Brasil se deu com a criação do Código de Defesa do Consumidor. Com a garantia dos direitos do consumidor, empresas e órgãos passaram a dar mais atenção à análise do seu público.

4 A figura do ouvidor surgiu na Suécia, no século XIX, com o papel do "semescal", um funcionário do rei que controlava as atividades dos juízes. No Brasil-Colônia existia o ouvidor-geral, que defendia os interesses da Coroa Portuguesa perante órgãos públicos e não atuava em favor do cidadão. 0 primeiro ouvidor-geral do Brasil foi Pero Borges, em 1549 (BARBOSA, 2008). 
Com dezenove anos de experiência em cobertura jornalística, voltada para a defesa dos direitos do consumidor, Celso Russomano identifica falhas nas ouvidorias. Ele avalia que o Código de Defesa do Consumidor não teve uma campanha de divulgação, patrocinada pelo governo, como teve o Código Brasileiro de Trânsito para explicar os direitos e deveres dos motoristas. O deputado acredita que, devido à falta de esclarecimento, a população recorre à imprensa para expor reclamações e denúncias, em vez de fazer uma queixa formal em uma ouvidoria pública.

O governo peca quando não dá a população o conhecimento de que existe um canal de comunicação. O ouvidor tem que ser independente e, em muitas situações, isso não ocorre. [...]. Então a população deixa de acreditar que o ouvidor seja realmente capaz de resolver. [...] Já a imprensa é um canal muito fácil de ser identificado, ela é pública, usa a concessão pública para denunciar. Ela tem uma velocidade muito maior, é mais acessível e tem um resultado efetivo. As pessoas veem resultados na televisão, a denúncia é feita e torna-se pública, na ouvidoria fica entre quatro paredes (RUSSOMANO, 2009).

Em suas reportagens, Russomano costuma fazer mediações de conflitos envolvendo consumidores e prestadores de serviço do setor privado. No entanto, os jornais comunitários abordam, predominantemente, serviços públicos.

Eu vejo alguns trabalhos, em sua maioria regionais, que prestam um serviço de utilidade pública, mas de maneira generalizada e voltada para questões do governo, [como] é o caso do "Balanço geral". Talvez o que falte para a cobertura de assuntos que envolvam o setor privado seja o conhecimento da legislação para poder se defender. E não é preciso saber da legislação para cobrar do serviço público. Se um hospital não suporta a demanda, é fácil identificar os problemas (RUSSOMANO, 2009).

\section{PORTA-VOZ DA POPULAÇÃO}

Para identificar práticas de jornalismo comunitário, analisamos dois programas do Distrito Federal: o "Balanço geral" (BG), da Rede Record, e o "DFTV $1^{\text {a }}$ edição”, da Rede Globo, ambos exibidos no horário do almoço e que têm em comum o viés comunitário.

O "Balanço geral” surgiu como um programa de rádio exibido na Bahia. O modelo foi transferido para a televisão pela Record de Salvador, há dezesseis anos. Em 2007, a emissora decidiu produzi-lo em sete praças, que atualmente já são 23. Apesar de terem peculiaridades distintas, é possível identificar uma que é comum a todas as versões: o caráter comunitário. Os programas preenchem critérios como a valorização da realidade local, a participação da comunidade e o poder de mobilização. No da Bahia, por exemplo, quadros como "A praça do povo", "Disk denúncia” e "O povo 
fala" abrem espaço para que o público se manifeste nas ruas, por telefone ou no estúdio, ao lado do apresentador.

O "BG Distrito Federal” também exibe quadros sobre denúncias de descaso, como "Assim não dá!", e permite que o telespectador conduza a reportagem no "Repórter comunidade". Guiliano Cartaxo, chefe de produção, afirma que quase todas as matérias partem de sugestões do público e que a participação é essencial para a produção:

Nós criamos vários meios de facilitar a participação do povo. Temos o telefone da redação que não para o dia todo, inclusive os celulares. Eu uso um celular da redação e já atendi ligação de telespectador às duas horas da manhã. [...] Hoje nós recebemos em média, mil ligações por dia. [...] Nós fizemos uma reportagem especial sobre o caos no transporte público no Distrito Federal e pedimos que as pessoas ligassem relatando situações que haviam vivido. Recebemos, em uma semana, 12.742 ligações (CARTAXO, 2009).

O “DFTV $1^{a}$ edição" é outro exemplo de jornalismo comunitário no Distrito Federal. O jornal é transmitido pela rede Globo entre $12 \mathrm{~h} 15$ e $12 \mathrm{~h} 45$, desde 1983. Além de noticias os acontecimentos diários, exibe quadros que têm como foco as demandas da comunidade. "Redação móvel", que estreou em março de 2009, exemplifica o viés comunitário. O quadro conta com um link (van com câmeras, monitores e equipamentos de transmissão ao vivo) que percorre a Capital Federal e toda a região do entorno, inserindo os jornalistas no cotidiano das comunidades. A van fica posicionada em pontos movimentados e abre espaço para que os moradores se manifestem sobre os maiores problemas do local. No final da semana, é feita uma triagem dos temas mais recorrentes, que serão transformados em reportagem.

A editora, Aliene Coutinho, cita a passagem do quadro no Riacho Fundo $\mathrm{II}^{5}$ em maio de 2009, quando foram recebidas 266 manifestações, entre pedidos de melhoria e denúncias sobre descaso. Uma delas foi do estudante Henrique Costa, que se dirigiu até a redação para fazer a pergunta "quando é que vão chegar os livros didáticos da $6^{a}$ série?” Ele se referia ao Centro de Ensino Fundamental I do Riacho Fundo II, que tem 2,6 mil alunos e não tinha recebido grande parte do material didático necessário. A reportagem, que foi ao ar no dia 8 de maio de 2009, procurou a Secretaria de Educação, a qual disponibilizou os livros no mesmo dia.

A passagem pelas comunidades do Distrito Federal permite que a imprensa detecte quais problemas são mais sentidos em cada região. Aliene Coutinho disse que no Riacho Fundo II o maior número de reclamações é sobre transporte público (37\%), seguido pelas que se referem à regularização de lotes (31\%) e à

5 Riacho Fundo Il é uma região administrativa do Distrito Federal criada em 1990. Tem cerca de 45 mil habitantes. Cf.: < http://www.riachofundoii.df.gov.br/001/00101001.asp?ttCD_CHAVE=202\&bt0peracao=>. 
melhoria da saúde pública (15\%). Em Sobradinho, outra região administrativa do Distrito Federal, o problema mais citado também é o transporte público (30\%), seguido pela segurança $(24 \%)$ e pela saúde pública $(22 \%)$.

Esse levantamento serve como pauta para outro quadro do "DFTV 1" edição": o "E se fosse você?", que propõe que o responsável conheça de perto as deficiências do serviço público. Por conta do grande número de reclamações sobre o transporte público, o jornal, no dia $1^{\circ}$ de junho de 2009 , mostrou o secretário de Transportes do Distrito Federal, Alberto Fraga, pegando o metrô, em Águas Claras ${ }^{6}$. Espremido no vagão, o secretário reconheceu as frágeis condições do metrô e se comprometeu em aumentar o número de vagões.

\section{CONSIDERAÇÕES FINAIS}

Os dois exemplos do Distrito Federal mostram que no jornal local é possível estreitar a relação com o público e ampliar a participação. Para se fazer jornalismo comunitário, é preciso abrir espaço para que as pessoas se manifestem e pautem os assuntos que serão noticiados. A imprensa local é capaz de produzir o jornalismo comunitário de modo eficiente quando estabelece contato direto com a população. Para Sequeira e Bicudo (2006, p. 8), o público confia nos jornais comunitários porque se sente inserido na produção. Ele deixa de ser

mero depositário de informações escolhidas e traduzidas por um grupo de iluminados e esclarecidos e passa, democraticamente, a ser encarado como cidadão protagonista, ativo, pensante e atuante. A hierarquia de certa forma se rompe e o diálogo se manifesta no sentido horizontal (com) e não na direção diagonal ou de cima para baixo (para).

Além de percorrer as comunidades e facilitar o acesso para que estas se exponham, a imprensa leva a reclamação ou denúncia até os responsáveis. Ela promove a comunicação entre o consumidor (povo) e o fornecedor (governo). E é exatamente essa a função de uma ouvidoria pública.

\section{REFERÊNCIAS}

BARBOSA, Marialva; HOHLFELDT, Antonio. Jornalismo no século XXI: a cidadania. Porto Alegre: Mercado Aberto, 2002. BOGO, Kellen Cristina. A história da internet: como tudo começou. 2000. Kplus. Disponível em: <http://kplus.cosmo.com.br/ materia.asp?co=11\&rv=Vivencia $>$. Acesso em: abr.. 2009 .

BRIGGS, Asa; BURKE, Peter. Uma história social da mídia: de Gutenberg à internet. Rio de Janeiro: Jorge Zahar, 2004.

CAMPOS, Pedro Celso. [Entrevista concedida em 20 set. 2006]. In: SEQUEIRA, Cleofe; BICUDO, Francisco. 2006. Jornalismo comunitário importância, conceitos e desafios contemporâneos. Disponível em: <http://www.observatoriodaimprensa.com.br/ artigos. asp?cod=405DAC004>. Acesso em: maio 2009

6 Criada na década de 1990, Águas Claras é a vigésima região administrativa do Distrito Federal. Tem cerca de75 mil habitantes. Cf.:<http://www.aguasclaras.df.gov.br/>. 
CARTAXO, Giuliano. [Entrevista concedida à autora]. Brasília, maio 2009.

COUTINHO, Aliene. [Entrevista concedida à autora por e.mail]. Maio 2009.

IMBROISI, Diniz de Oliveira. Ouvidoria como instrumento de eficiência e eficácia da administração pública. 2004. Disponível em: $<$ http://www.abonacional.org.br/Vlenc_paineis.asp?vpro=fazenda >. Acesso em: abr. . 2009 .

KOVACH, Bill; ROSENSTIEL, Tom. Elementos do jornalismo. São Paulo: Geração Editorial, 2004.

MESQUITA, Mário; TRAQUINA Nelson. Jornalismo cívico. Lisboa: Novo Horizonte, 2003.

PENA, Felipe. Teoria do jornalismo. São Paulo: Contexto, 2004.

QUADROS, Claudia Irene de. Uma breve visão histórica do jornalismo on-line. In: BARBOSA, Marialva; HOHLFELDT, Antonio. Jornalismo no século XXI: a cidadania. Porto Alegre: Mercado Aberto, 2002.

RUSSOMANO, Celso Ubirajara. [Entrevista concedida à autora]. .Brasília, ,maio 2009

SEQUEIRA, Cleofe; BICUDO, Francisco. 2006. Jornalismo comunitário importância, conceitos e desafios contemporâneos. Disponível em: < http://www.observatoriodaimprensa.com.br/artigos.asp?cod=405DAC004 > . Acesso em: maio 2009.

Recebido em: 15.12.2009 / Aceito em: 16.03.2010 